\title{
Value of magnetic resonance spectroscopy in assessment of adnexal lesions
}

\author{
Rania S. M. Ibrahim", Marwa Sh. Abd El Fattah', Zeinab M. Metwally² and Lamiaa A. S. Eldin ${ }^{1}$
}

\begin{abstract}
Background: The purpose of this study is to investigate the role of proton MR spectroscopy (1H-MRS) in the characterization and diagnosis of ovarian lesions.

Results: From October 2015 to October 2017, a total of 57 female patients (65 adnexal lesions; 8 cases were bilateral) were included. The examined lesions were classified according to their histopathological findings, (37 (57\%) benign lesions, 4 (6\%) borderline lesions, and 24 (37\%) malignant lesions). The mean choline/creatinine (CHO/ $\mathrm{Cr}$ ) ratio was $1.29 \pm 0.98 \mathrm{SD}$ for malignant lesions, while the mean value in borderline lesions was $0.63 \pm 0.15 \mathrm{SD}$, and the mean value for the benign lesions was $0.65 \pm 0.34$. Therefore, the mean $\mathrm{CHO} / \mathrm{Cr}$ ratio was much higher in malignant than in benign lesions, which was statistically significant $(P \leq 0.001)$ as well as between the borderline and invasive lesions $(P=0.05)$, but not between the benign and borderline lesions. The diagnostic performance of conventional MRI in diagnosing adnexal lesions was $100 \%$, specificity was $76 \%$, and accuracy was $86 \%$. However, MRS individual diagnostic performances are the following: sensitivity $89 \%$, specificity, and $100 \%$ with an accuracy of 95\%.

Conclusion: MRS proved to be an accurate and efficient method for the analysis of adnexal lesions and in differentiation between benign and malignant tumors.
\end{abstract}

Keywords: Magnetic resonance spectroscopy, Adnexal lesions, Preoperative

\section{Background}

Ovarian cancer is the fifth leading cause of cancer death among women. It is a malady of post-menopausal women and prepubescent girls. Risk factors embrace an age over 50 , positive family history, infertility, and previous cancer. Ovarian malignancy typically discovered at the late stage with a 5-year survival rate of $20 \%$. The 5year survival rate can improve to $90 \%$ if the disease is discovered in an earlier stage (stage I) [1].

Most malignant ovarian tumors are primary $(95 \%)$, being epithelial in origin (90\%). The epithelial tumors are classified into serous, mucinous, endometrioid, clear cell, and undifferentiated, while the non-epithelial tumors embrace sex cord-stromal tumors and germ cell tumors. Some primary tumors (e.g., gastric and colorectal, breast, pancreas, and melanoma) can metastasize to the ovary [2].

\footnotetext{
* Correspondence: raniasaberm@hotmail.com

${ }^{1}$ Radiology Department, Kasr El-Ainy Hospital, Cairo University, Cairo, Egypt Full list of author information is available at the end of the article
}

MRI becomes an important method of investigation of ovarian lesions with high sensitivity (97\%) and specificity (84\%) in characterizing malignant lesions and identifying indeterminate lesion [3]. MRS can detect metabolic and molecular changes which often precede morphologic alterations, so sensitivity is expected to be improved by MRS [4].

\section{Methods}

A prospective study was performed on 57 patients (65 adnexal lesions; 8 cases were bilateral) were presented with adnexal lesions and referred from the Gynecology department to the Radiology department (Women's Imaging Unit) based on preliminary trans-vaginal and/ or trans-abdominal US examination used to exclude the patients with anechoic unilocular cysts. They were complaining of different complaints such as lower abdominal pain, abdominal enlargement, vaginal bleeding, and 1ry infertility. Pelvic MRI with MRS was done for all patients. Fifty-two (52) patients underwent surgery with pathologic correlation; five 
cases had a clinical and US follow-up: (hyper-stimulated ovaries, inclusion cyst, multiple follicular cysts, hemorrhagic corpus luteum cyst, and endometrioma), all these 5 lesions were regressed or disappeared on follow-up study. This study was conducted the period from October 2015 to 2017.

MRI was performed on a 1.5-T MRI unit (Achieva, Philips medical system). All the patients were imaged in the supine position with the aid of pelvic-phased array coil.

\section{Patient preparation}

Patients were instructed to fast for $3 \mathrm{~h}$ and void urinating $2 \mathrm{~h}$ prior to the examination. Intravenous administration of $10 \mathrm{mg}$ of an antispasmodic drug was given before MRI to reduce bowel peristalsis.

\section{Conventional MR imaging (c MRI) protocol}

- Axial T1-weighted (TR/TE = 700-750/10-20).

- Axial T 2-weighted (TR/TE $=3000-3700 / 90-110)$.

- Sagittal T2-weighted.

- Coronal T2-weighted.

- Post-contrast fat-suppressed T1WI with slice thickness $(5-15 \mathrm{~mm})$, gap $(1-2 \mathrm{~mm})$ field of view (20$40 \mathrm{~cm})$, and matrix size $(128 \times 256)$.

- By c MRI, we classified the lesions as benign or malignant tumors according to the following criteria:

- Morphology of the tumor, either pure cystic or complex lesion.

- Involvement of one or both ovaries.

- Size of the lesion

- Signal intensity of the tumor.

- Enhancement of the solid component.

- Wall thickness and regularity of the tumor and its enhancement.

- Presence of vegetations and septations, their enhancement pattern, and their size.

- Presence of ascites.

- Presence of infiltrated pelvic or para-aortic lymph nodes.

- Involvement of other pelvic organs.

- Presence of peritoneal and omental deposit.

- MRS was performed in all cases. After the identification of adnexal masses on axial or sagittal T2-weighted imaging, using multi-voxel point resolved surface coil spectroscopy for volume localization with TE (144 and $288 \mathrm{~ms})$, number of excitations $=6$, interpolated voxel $5 \times 5 \times 5 \mathrm{~mm}^{3}$ to detect metabolites with long and intermediate T2 relaxation times such as NAA, $\mathrm{CHO}, \mathrm{Cr}$, and lactate. The region of interest (ROI) for MRS measurement was placed at the center of the lesion to avoid contamination signals from peripheral tissues; the target area without obvious hemorrhage, necrosis, and cystic component by referring to orthogonal c MRI.

\section{Interpretation of MRS}

(a) Qualitative analysis: Patient spectra were interpreted qualitatively by inspection of the peaks.

(b) Quantitative analysis: Another approach was the quantitative approach using the integral ratios $(\mathrm{CHO} / \mathrm{Cr})$. Concentrations of $\mathrm{CHO}, \mathrm{Cr}$, lipid, and lactate were evaluated. Authors were blinded about each other imaging findings and they were not aware of the pathology.

\section{Statistical analysis}

Data were coded and entered using the statistical package SPSS (Statistical Package for the Social Sciences) version 23. Data was summarized using mean, standard deviation, median, minimum and maximum in quantitative data, and using frequency (count) and relative frequency (percentage) for categorical data. Comparisons between quantitative variables were done using the nonparametric Kruskal-Wallis and Mann-Whitney tests. For comparing categorical data, chi-square $\left(\chi^{2}\right)$ test was performed. The exact test was used instead when the expected frequency is less than 5. Standard diagnostic indices including sensitivity, specificity, positive predictive value (PPV), negative predictive value (NPV), and diagnostic efficacy were calculated. $P$ values less than 0.05 were considered as statistically significant.

\section{Results}

This study included 65 ovarian lesions in 57 female patients ( 8 cases showed bilateral lesions). The patient's age ranged from 15 to 70 years old (mean age 34.8 ( \pm 14.76$) \mathrm{SD})$. The examined lesions were classified according to their pathological findings as previously described criteria in patient and methods into (37 (57\%) benign lesions, 4 (6\%) borderline lesions, 24 (37\%) malignant lesions (Table 1).

- The benign tumors included: Nine serous cystadenomas, two mucinous cystadenomas, nine tubo-ovarian abscesses, nine mature cystic teratomas, two broad ligament fibroids, one granulosa cell tumor, one endometrioma, one hemorrhagic corpus luteal cyst, one multifollicular cyst, one inclusion cyst, and one hyper-stimulated ovary)

- The borderline tumors were: three borderline papillary serous cystadenomas and one borderline papillary mucinous cystadenoma. 
Table 1 The pathological subtype of the adnexal lesions included in the study

\begin{tabular}{|c|c|c|c|}
\hline \multicolumn{3}{|l|}{ Pathology } & \multirow{2}{*}{$\begin{array}{l}\text { No. of the lesions } \\
9\end{array}$} \\
\hline Benign $(n=37)$ & Epithelial & Serous & \\
\hline & & Mucinous & 2 \\
\hline & Sex cord stromal & Granulosa cell tumor & 1 \\
\hline & Germ cell tumor & Mature cystic teratoma & 9 \\
\hline & Inflammatory & Tubo-ovarian abscess & 9 \\
\hline & & Broad ligament fibroid & 2 \\
\hline & & Endometrioma & 1 \\
\hline & & Hemorrhagic corpus luteum cyst & 1 \\
\hline & & Multiple follicular cysts & 1 \\
\hline & & Inclusion cyst & 1 \\
\hline & & Hyper stimulated ovaries & 1 \\
\hline \multirow{2}{*}{$\begin{array}{l}\text { Border } \\
\text { line } \\
(n=4)\end{array}$} & Epithelial & Serous & 3 \\
\hline & & Mucinous & 1 \\
\hline \multirow{6}{*}{$\begin{array}{l}\text { Malignant } \\
(n=24)\end{array}$} & Epithelial & Serous & 11 \\
\hline & & Mucinous & 6 \\
\hline & & Malignant Brenner tumor & 2 \\
\hline & Sex cord stromal & Granulosa cell tumor & 2 \\
\hline & Germ cell tumor & Dysgerminoma & 2 \\
\hline & & Immature teratoma & 1 \\
\hline Total & & & 65 \\
\hline
\end{tabular}

- The malignant tumors included: eleven papillary serous cystadenocarcinomata, six mucinous cystadenocarcinomata, two malignant Brenner tumors, two granulosa cell tumors, two dysgerminomas, two endometrioid carcinomata, and one immature teratoma).

\section{MRI findings (Table 2)}

- Regarding the size of the lesion: Maximum diameter (mean \pm SD) for benign adnexal lesions is ranging about 2-17 cm (8.2 \pm 3.5$)$, for borderline lesions 6$15 \mathrm{~cm}(7.5 \pm 3.3)$ and for malignant lesions $6-25 \mathrm{~cm}$ (13.6 \pm 8.06$)$.

- Regarding their morphology: they were classified between predominantly multi-locular cystic lesions (62\%), mixed cystic/solid lesions (23\%), and solid lesions $(15 \%)$.

- MRI variable T2 signal: a low signal in 5\%, a mixed intermediate signal in 35\%, and a hyperintense $\mathrm{T} 2$ signal was seen in $60 \%$.

- On post-contrast enhancement: The complex adnexal masses showed variable contrast uptake either avidly enhanced (25\%), moderately enhanced (32\%), mildly enhanced (23\%), or no appreciable enhancement (20\%).
- Regarding associated findings: ascites were found in $31 \%$, peritoneal implants in $5 \%$, and lymphadenopathy $11 \%$, the last two findings were found exclusively in malignant adnexal lesions.

\section{MRS findings}

Multi-voxel MRS was performed in all cases with qualitative and quantitative analysis of the detected peaks.

\section{Qualitative assessment}

We assessed the metabolites' peaks (CHO, NAA, Cr, lactate, and lipid) in 65 lesions (Tables 3, 4, 5, and 6).

- $\mathrm{CHO}$ peak was present in 42 lesions (64.5\%), including 17 benign (40\%), 22 malignant (53\%), and 3 borderline (7\%) lesions.

- $\mathrm{N}$-acetyl aspartate (NAA) was present in 49 lesions out of the 65 (75\%), including 26 benign (53\%), 3 borderline (6\%), and 20 malignant (41\%) lesions.

\section{Quantitative assessment}

A multi-voxel study was done including most of the lesion including its solid and cystic components. Then, the metabolite peaks were qualitatively assessed in relation to the baseline (average noise level). And the mean $\mathrm{CHO} / \mathrm{Cr}$ ratios were calculated for every pathological group (Table 7). 
Table 2 Conventional MRI Morphologic characteristics of adnexal lesions included in the study

\begin{tabular}{llll}
\hline MRI features & Benign lesions & Borderline lesions & Malignant lesions \\
\hline Maximum diameter (cm), mean \pm SD & $2-17(8.2 \pm 3.5)$ & $6-15(7.5 \pm 3.3)$ & $6-25(13.6 \pm 8.06)$ \\
Morphology & & & $6(25 \%)$ \\
$\quad$ Predominantly complex cystic & $34(91 \%)$ & & $14(58 \%)$ \\
Mixed cystic and solid & $1(3 \%)$ & $4(100 \%)$ & $4(17 \%)$ \\
$\quad$ Solid & $2(6 \%)$ & & $1(25 \%)$ \\
Signal intensity on T2 & & $1(25 \%)$ & $16(67 \%)$ \\
Low & $2(5 \%)$ & $2(50 \%)$ & $8(33 \%)$ \\
IM & $6(16 \%)$ & & $14(58 \%)$ \\
High & $29(79 \%)$ & $3(75 \%)$ & $10(42 \%)$ \\
Enhancement & $13(36 \%)$ & $1(25 \%)$ & $16(67 \%)$ \\
No & $12(32 \%)$ & & $3(12.5 \%)$ \\
Mild & $6(16 \%)$ & $1(25 \%)$ & $7(29 \%)$ \\
Moderate & $6(16 \%)$ & & \\
Avid & $3(8 \%)$ & & \\
Ascites & & & \\
Peritoneal implants & & & \\
Lymphadenopathy & & & \\
\hline
\end{tabular}

We compared the number of cases which was diagnosed by the c MRI as benign or malignant tumors according to the criteria mentioned before in patients and methods; with those diagnosed depending on the MRS. The results were compared with the pathology which is considered the main reference.

C MRI suggested malignant pathology in 37 cases; 28 of them were TP (24 of them were true malignant and 4 of them were borderline tumors), while 9 were benign and diagnosed as being malignant (FP). C MRI suggested benign pathology in 28 cases; all of them were benign (TN) (Table 8).

MRS suggested malignancy in 25 cases all of them were TP, MRS suggested benign pathology in 40 cases; 37 of them were benign (TN), misdiagnosed 3 cases were malignant and diagnosed as being malignant (FN) (Table 8).

The diagnostic performance values including sensitivity, specificity, PPV, NPV, and accuracy were calculated

Table 3 Metabolites detected by MRS curves

\begin{tabular}{lll}
\hline Component detected & No of cases & $\%$ \\
\hline $\mathrm{CHO}^{\mathrm{a}}$ & 42 & $64.5 \%$ \\
$\mathrm{Cr}^{\mathrm{b}}$ & 19 & $29.0 \%$ \\
Lactate & 53 & $81.5 \%$ \\
Lipid & 65 & $100.0 \%$ \\
$\mathrm{NAA}^{c}$ & 49 & $75 \%$ \\
\hline
\end{tabular}

${ }^{\mathrm{a}} \mathrm{CHO}$ choline, ${ }^{\mathrm{b}} \mathrm{Cr}$ creatine, ${ }^{\mathrm{c}} \mathrm{NAA} \mathrm{N}$-acetyl aspartate for c MRI and MRS, we detect differences between both of them (Table 9).

The evaluation of MRI and MRS data in these $57 \mathrm{pa}$ tients (65 lesions) shown similarity in 28 benign cases but they differ in 9 particular benign cases as MRI evaluated them as being suspicious while MRS evaluated them as being benign so MRI-MRS final diagnosis changed from being suspicious to benign, and they all pathologically proved to be benign (4 cases of benign serous cystadenoma, 2 cases of broad ligament fibroid, 1 tuboovarian abscess, 1 endometrioma, and a case of granulosa cell tumor).

MRI and MRS data showed similarity in 25 malignant cases but they differ in 3 particular malignant cases as MRI evaluated them as being suspicious while MRS evaluated them as being benign and they all pathologically proved to be (2 borderline serous cyst adenoma and one malignant immature teratoma). The final MRI-MRS diagnosis considered them as borderline cases.

\section{Discussion}

Differentiation of an adnexal mass into benign and malignant is the primary role of imaging modalities. Proper diagnoses will direct patients to the appropriate treatment algorithm to reduce the number of women unnecessarily undergoing cancer surgery, to preserve fertility in young women (by allowing laparoscopy) [2]. 
Table 4 Metabolites detected in the thirty seven benign cases after correlation with the pathology results

\begin{tabular}{|c|c|c|c|c|c|c|}
\hline \multirow[t]{2}{*}{ Histopathology } & \multirow[t]{2}{*}{ No. } & \multicolumn{5}{|c|}{ Metabolite detected } \\
\hline & & $\overline{\mathrm{CHO}^{\mathrm{a}}}$ & $\mathrm{Cr}^{\mathrm{b}}$ & Lactate & Lipid & $\mathrm{NAA}^{\mathrm{C}}$ \\
\hline Mature cystic teratoma & 9 & $+(n=3)$ & $+(n=7)$ & $+(n=8)$ & $++(n=9)$ & $++(n=5)$ \\
\hline Serous cyst adenoma & 9 & $+(n=6)$ & $+(n=7)$ & $+(n=3)$ & $+(n=9)$ & $++(n=6)$ \\
\hline Mucinous cyst adenoma & 2 & $+(n=2)$ & $+(n=2)$ & $+(n=2)$ & $+(n=2)$ & $++(n=2)$ \\
\hline Broad ligament fibroid & 2 & $+(n=1)$ & - & $+(n=2)$ & $+(n=2)$ & - \\
\hline Granulosa cell tumor & 1 & - & - & $+(n=1)$ & $+(n=1)$ & $+(n=1)$ \\
\hline Tubo-ovarian abscess & 9 & $+(n=5)$ & - & $+(n=7)$ & $+(n=9)$ & $++(n=7)$ \\
\hline Endometrioma & 1 & - & - & $+(n=1)$ & $+(n=1)$ & $+(n=1)$ \\
\hline Hemorrhagic corpus luteum cyst & 1 & - & - & $+(n=1)$ & $+(n=1)$ & $+(n=1)$ \\
\hline Multiple follicular cysts & 1 & - & - & $+(n=1)$ & $+(n=1)$ & $+(n=1)$ \\
\hline Inclusion cyst & 1 & - & - & $+(n=1)$ & $+(n=1)$ & $+(n=1)$ \\
\hline Hyperstimulation syndrome & 1 & - & - & - & $+(n=1)$ & $+(n=1)$ \\
\hline
\end{tabular}

${ }^{a} \mathrm{CHO}$ choline, ${ }^{\mathrm{b}} \mathrm{Cr}$ creatine, ${ }^{\mathrm{c}} \mathrm{NAA} \mathrm{N}$-acetyl aspartate

MRI had helped in identifying malignant lesions before surgery, particularly if an indeterminate lesion was discovered by the US. MRI can reveal morphologic characteristics (e.g., papillary projections, nodularity, septa, solid portions, and signal intensity), but these criteria are unreliable in differentiating between benign and malignant tumors [5]. MRS can offer information concerning cellular integrity, cell proliferation or degradation, and energy metabolism of tissues [6]. MRS can detect metabolic and molecular features and precede morphologic alterations characteristic of malignancy, so sensitivity is expected to be improved by adding MRS [4].

The current study was performed on 57 patients having 65 adnexal masses (bilaterally 8 cases) at the US. The patient's age ranged from 15 to 70 years old (mean age $34.80 \pm 14.76 \mathrm{SD}$ ). Pelvic MRI with MRS was done for all patients. Fifty-two (52) patients underwent surgery with pathologic correlation; the other five cases had a clinical and the US follow-up. We classified the detected adnexal lesions into 37 benign, 4 borderline, and 24 malignant lesions (Table 1).

In this study, the detected adnexal lesions varied in their mean maximum diameter \pm SD (benign lesions ranging about $2-17 \mathrm{~cm}(8.2 \pm 3.5)$, borderline lesions $6-$ $15 \mathrm{~cm}$ (7.5 \pm 3.3$)$, and malignant lesions $6-25 \mathrm{~cm}$ $(13.6 \pm 8.0)$ (Table 2).
Regarding their morphology, they were classified into predominantly multi-locular cystic lesions; 40 lesions (62\%), mixed cystic/solid lesions; 15 lesions (23\%), and solid lesions; 10 lesions (15\%) (Table 2).

MRI was done to all cases with a variable T2 signal; a low signal in 3 lesions (5\%), a mixed intermediate signal in 23 lesions (35\%), and a hyper-intense T2 signal were seen in 39 lesions (60\%). On post-contrast enhancement, the complex adnexal masses showed variable contrast uptake either avidly enhanced in 16 lesions (25\%), moderately enhanced in 21 lesions (32\%), mildly enhanced in 15 lesions (23\%), or no appreciable enhancement in 13 lesions (20\%) (Table 2).

The MRI features for the diagnosis of malignancy are a large solid component, wall thickness larger than $3 \mathrm{~mm}$, a septal thickness over $3 \mathrm{~mm}$, and/or nodularity and necrosis. Supportive criteria can help in differentiating a tumor as malignant one; this embraces the involvement of pelvic organs or sidewall; peritoneal, mesenteric, or omental disease; and ascites and adenopathy [7]. In this study, 20 cases associated with ascites, 7 cases associated with lymphadenopathy, and 3 cases with peritoneal implants (pathologically proved to be 2 cases of malignant serous cystadenocarcinomata and a case of malignant immature teratoma) (Table 2).

Borderline epithelial ovarian tumors (BEOTs) are tumors of low malignant potential. They are characterized

Table 5 Metabolites detected in the four borderline cases

\begin{tabular}{|c|c|c|c|c|c|c|}
\hline \multirow[t]{2}{*}{ Histopathology } & \multirow[t]{2}{*}{ NO. } & \multicolumn{5}{|c|}{ Metabolite detected } \\
\hline & & $\overline{\mathrm{CHO}^{\mathrm{a}}}$ & $\mathrm{Cr}^{\mathrm{b}}$ & Lactate & Lipid & $\mathrm{NAA}^{\mathrm{C}}$ \\
\hline Borderline serous cyst adenoma & 3 & $+(n=2)$ & $+(n=2)$ & $+(n=2)$ & $+(n=3)$ & $+(n=2)$ \\
\hline Borderline mucinous cyst adenoma & 1 & $+(n=1)$ & $+(n=1)$ & $+(n=1)$ & $+(n=1)$ & $+(n=1)$ \\
\hline
\end{tabular}

${ }^{\mathrm{a}} \mathrm{CHO}$ choline, ${ }^{\mathrm{b}} \mathrm{Cr}$ creatine, ${ }^{\mathrm{C}} \mathrm{NAA} \mathrm{N}$-acetyl aspartate 
Table 6 Metabolites detected in the twenty four malignant cases

\begin{tabular}{|c|c|c|c|c|c|c|}
\hline \multirow[t]{2}{*}{ Histopathology } & \multirow[t]{2}{*}{ No. } & \multicolumn{5}{|c|}{ Metabolite detected } \\
\hline & & $\overline{\mathrm{CHO}^{\mathrm{a}}}$ & $\mathrm{Cr}^{\mathrm{b}}$ & Lactate & Lipid & $\mathrm{NAA}^{\mathrm{c}}$ \\
\hline Serous cystadenocarcinoma & 11 & $++(n=10)$ & - & $+(n=11)$ & $+(n=11)$ & $+(n=10$ \\
\hline Mucinous cystadenocarcinoma & 6 & $++(n=6)$ & - & $+(n=6)$ & $+(n=6)$ & $+(n=4)$ \\
\hline Malignant immature teratoma & 1 & - & - & - & $+(n=1)$ & - \\
\hline Dysgerminoma & 2 & $+(n=2)$ & - & $+(n=2)$ & $+(n=2)$ & $+(n=2)$ \\
\hline Malignant Brenner tumor & 2 & $+(n=2)$ & - & $+(n=2)$ & $+(n=2)$ & $+(n=2)$ \\
\hline Granulosa cell tumor & 2 & $+(n=2)$ & - & $+(n=2)$ & $+(n=2)$ & $+(n=2)$ \\
\hline
\end{tabular}

${ }^{\mathrm{a}} \mathrm{CHO}$ choline, ${ }^{\mathrm{b}} \mathrm{Cr}$ creatine, ${ }^{\mathrm{c}} \mathrm{NAA} \mathrm{N}$-acetyl aspartate

by atypical epithelial proliferation, moderate nuclear atypia, however, without stromal invasion. Patients with BEOTs are discovered with an early stage disease, and have an excellent prognosis one surgical excision; however, they have a high recurrence rate. It is necessary to preoperatively differentiate BEOTs because a conservative fertility-sparing laparoscopic surgery can be done [8].

A study done by Lyer et al. (2010) revealed that the preoperative diagnosis of borderline tumors is rare because they lack diagnostic imaging features. On MRI, borderline tumors are predominantly cystic, with fluid ranging in $\mathrm{T} 1$ and $\mathrm{T} 2$ signal because of varying concentrations of protein and mucin. There are also multiple enhanced solid mural nodules or thick septa. There is no proof of lymphadenopathy, ascites, or peritoneal implants [9].

In this study, BOTs were a great challenge for us. Their morphological features can mimic benign or malignant lesions, yet they lack the invasive behavior of the malignant lesions. In functional imaging, some of them mimic benign lesions, which is consistent with their non-invasive behavior. The papillary projections were detected in three cases, MRI diagnosed two of them towards borderline to malignant lesions and one lesion to be sure malignant, while MRS showed lactate, lipid, and NAA peaks with no significant differences in the values between benign and borderline masses so MRS evaluated them as benign masses. The final MRI-MRS diagnosis considered them as borderline cases. So the difference between MRI and MRS data can suspect borderline tumors in which suspicious features can be

Table 7 The mean values of the $\mathrm{CHO} / \mathrm{Cr}$ ratio, $P$ value 0.001 (significance $<0.05$ )

\begin{tabular}{llll}
\hline & Minimum & Maximum & Mean $\left( \pm \mathrm{SD}^{\mathrm{a}}\right)$ \\
\hline Benign & 0.02 & 1.5 & $0.65 \pm 0.34$ \\
Borderline & 0.4 & 0.8 & $0.63 \pm 0.15$ \\
Malignant & 0.25 & 2.5 & $1.29 \pm 0.98$ \\
\hline
\end{tabular}

${ }^{\mathrm{a}} \mathrm{SD}$ standard deviation detected in MRI while no metabolic levels indicate malignancy can be detected in MRS.

A study conducted by MA and colleagues in 2015 on 69 patients showed $\mathrm{CHO}$ peak was detected in all 69 cases (100\%), NAA peak in 67 cases (97\%, 25 benign and 42 malignant), lipid peak in 47 cases (17 benign and 30 malignant), and lactate peak in 8 cases (4 benign and 4 malignant) [10].

In this study, $\mathrm{CHO}$ peak was detected in 42 cases (64.5\%) (17 benign (40\%), 22 malignant (53\%), and 3 borderline (7\%) lesions), Cr peak in 19 cases (29\%), NAA peak in 49 cases (75\%) (26 benign (53\%), 3 borderline (6\%), and 20 malignant (41\%) lesions), lipid peak in all cases $(100 \%)$, and lactate peak in 53 cases $(81.5 \%)(27$ benign (51\%), 3 borderline (6\%), and 23 malignant (43\%) lesions (Tables 3, 4, 5, and 6).

$\mathrm{CHO}$ is a cell membrane marker observed at $3.2 \mathrm{ppm}$. It reflects the biochemical activity of cell membranes. Increased $\mathrm{CHO}$ probably reflects the increased number of cells and/ or cell membrane synthesis [11]. El Sorogy et al. (2012) have reported that Cho peak was detected in all solid tumor or solid parts in cystic tumors. However, the Cho peak was also found in benign tumors so, it could not be used for the differentiation between benign and malignant tumors. Ovarian lesions have shown significantly higher levels of Cho in malignant lesions compared to the benign ones, may be due to tumor cell proliferation and increased cellularity and growth. However, it was also detected in some benign lesions such as mature cystic teratomas [4]. A similar study conducted by Malek et al (2015) on 23 ovarian masses showed the presence of Cho peak in 17 of 19 malignant masses

Table 8 The correlation between the numbers of cases diagnosed as benign or malignant by conventional MR imaging, MRS, and pathology

\begin{tabular}{llllll}
\hline & $\mathrm{TP}^{\mathrm{a}}$ & $\mathrm{TN}^{\mathrm{b}}$ & $\mathrm{FP}^{\mathrm{c}}$ & $\mathrm{FN}^{\mathrm{d}}$ & $\mathrm{TOTAL}$ \\
\hline Conventional MRI & 28 & 28 & 9 & 0 & 65 \\
MRS & 25 & 37 & 0 & 3 & \\
Pathology & 28 & 37 & 0 & 0 & \\
\hline
\end{tabular}

${ }^{\mathrm{a}} T P$ true positive, ${ }^{\mathrm{b}} T N$ true negative, ${ }^{\mathrm{c}} F P$ false positive, ${ }^{\mathrm{d}} F N$ false negative 
Table 9 Diagnostic performance values of conventional MRI and MRS in the assessment of adnexal lesions

\begin{tabular}{lll}
\hline & Conventional MRI & MRS \\
\hline Sensitivity & 100 & 89 \\
Specificity & 76 & 100 \\
PPV $^{a}$ & 76 & 100 \\
NPV $^{b}$ & 100 & 93 \\
Accuracy & 86 & 95 \\
\hline
\end{tabular}

${ }^{\mathrm{a}} P P V$ positive predictive value, ${ }^{\mathrm{b}} N P P$ negative predictive value

(sensitivity $89 \%$ ) and in 3 of 4 benign masses. So it could not be used in differentiation between benign and malignant tumors [12].

In this study, $\mathrm{CHO}$ peak was detected in 42 lesions (64.5\%) including 17 (40\%) benign lesions (5 abscesses, 3 mature teratomas, 2 mucinous and 6 serous cystadenomas (Fig. 2), 1 broad ligament fibroid), three borderline (7\%) lesions. It was above the noise level but lower than twofold. In 22 malignant lesions (53\%), sharp peaks were found in serous and mucinous cystadenocarcinomas. So $\mathrm{CHO}$ peak could not help in differentiation between benign and malignant tumors (Tables 3, 4, 5, and 6).

Regarding $\mathrm{CHO} / \mathrm{Cr}$ ratio a study conducted by $\mathrm{El}$ Sorogy et al. (2012) showed that the mean ratios of the malignant ovarian masses were significantly higher than benign ovarian masses with a sensitivity $83 \%$, and specificity $82 \%$ [4]. Another study conducted by Stanwell et al. (2008) showed a higher $\mathrm{CHO} / \mathrm{Cr}$ ratio in malignant than in benign cystic ovarian tumors except for one patient who had a serous cystadenofibroma and the $\mathrm{CHO} / \mathrm{Cr}$ ratio was 3.13. The benign tumors had a $\mathrm{CHO} / \mathrm{Cr}$ ratio $\leq 1.15$ for both solid and cystic components. All malignant tumors had the $\mathrm{CHO} / \mathrm{Cr}$ ratio $\geq 3.09$ for both solid and cystic tumors [13].

In the current study, mean $\mathrm{CHO} / \mathrm{Cr}$ ratio was $1.29 \pm 0.98 \mathrm{SD}$ for malignant lesions, while the mean value in borderline lesions was $0.63 \pm 0.15 \mathrm{SD}$ and the mean value for the benign lesions was $0.65 \pm 0.34$ (Fig. 2). The mean $\mathrm{CHO} / \mathrm{Cr}$ ratio was much higher in malignant than in benign lesions; which was statistically significant $(P \leq 0.001)$ as well as between the borderline and invasive lesions $(P=0.05)$, but not between the benign and borderline lesions (Table 7).

NAA is found in high concentration within the nervous system [14]. NAA is reverberant at $2.0 \mathrm{ppm}$, it is called neuronal marker [15]. Some studies [16] detected NAA metabolites in both solid and cystic elements of the mucinous cystadenoma. A study conducted by El Sorogy et al. (2012) also detected the NAA signal in all cases of mature cystic teratomas, denoting the presence of a neural component (ectodermal tissue) [4]. Also, a study conducted by Stanwell et al. (2008) reported the presence of NAA in all of the teratomas and serous cyst-adenomas, as well some of the serous carcinomas. We agreed with this study, as sharp NAA peaks were found in mature cystic teratomas, serous and mucinous cystadenomas, and tubo-ovarian abscesses. NAA peak was also detected in 3 borderline tumors and most malignant tumors (20 lesions) [13] (Fig. 3).

Lipids are not detectable in the spectrum of a healthy human. Some pathologic conditions yield lipid signals at 0.9 and $1.3 \mathrm{ppm}$ [9]. Both studies conducted by Okada et al. (2001) and Fiaschetti et al., (2012) agreed in observation of lipid peak in lesions with high serous content and teratoma which is reflecting a high content of the fatty component. It was in agreement with our study; a lipid peak was detected in all the cases (100\%) but values were higher in cases of mature cystic teratoma which reflects a high fatty component of the tumor [17, 18] (Fig. 1).

Lactate is the end-product of anaerobic glycolysis and appears at $1.3 \mathrm{ppm}$ [12]. Lactate signal is detected in the cystic portion of the ovarian tumors which were detected not only in all malignant tumors but also in some benign tumors as in dermoid cysts. A previous study was done by Hascalik et al. (2005) demonstrated that lactate signals were detected in some benign tumors; but, all cases of malignant tumors showed lactate and attended higher peaks than benign tumors [19]. In the current study, there was agreement with the previous studies. A sharp lactate peaks were found in serous benign lesions, tuboovarian abscesses, broad ligament fibroids, and solid portions of the borderline lesions, as well as the solid portions of the malignant serous and mucinous cystadenocarcinoma lesions (Fig. 1), but the value detected in the malignant case was much higher than the value detected in any of the benign cases. Therefore, when no lactate signals were detected; there is a very low probability of malignancy and the lactate signal might be used in differentiation between malignant and benign tumors.

In this study, c MRI suggested malignant pathology in 37 masses; 28 of them were true malignant (TP) (24 of them were true malignant and 4 of them were borderline tumors), while 9 were benign but were faulty diagnosed as being malignant (FP) (4 cases of benign serous cystadenoma (Fig. 2), 2 cases of broad ligament fibroid, 1 tubo-ovarian abscess, 1 endometrioma (Fig. 3), last case of granulosa cell tumor (Fig. 4). C MRI also suggested benign pathology in 28 cases; all of them were true benign (TN) (Table 8).

MRS suggested malignancy in 25 cases; all of them were TP, however, it suggested benign pathology in 40 

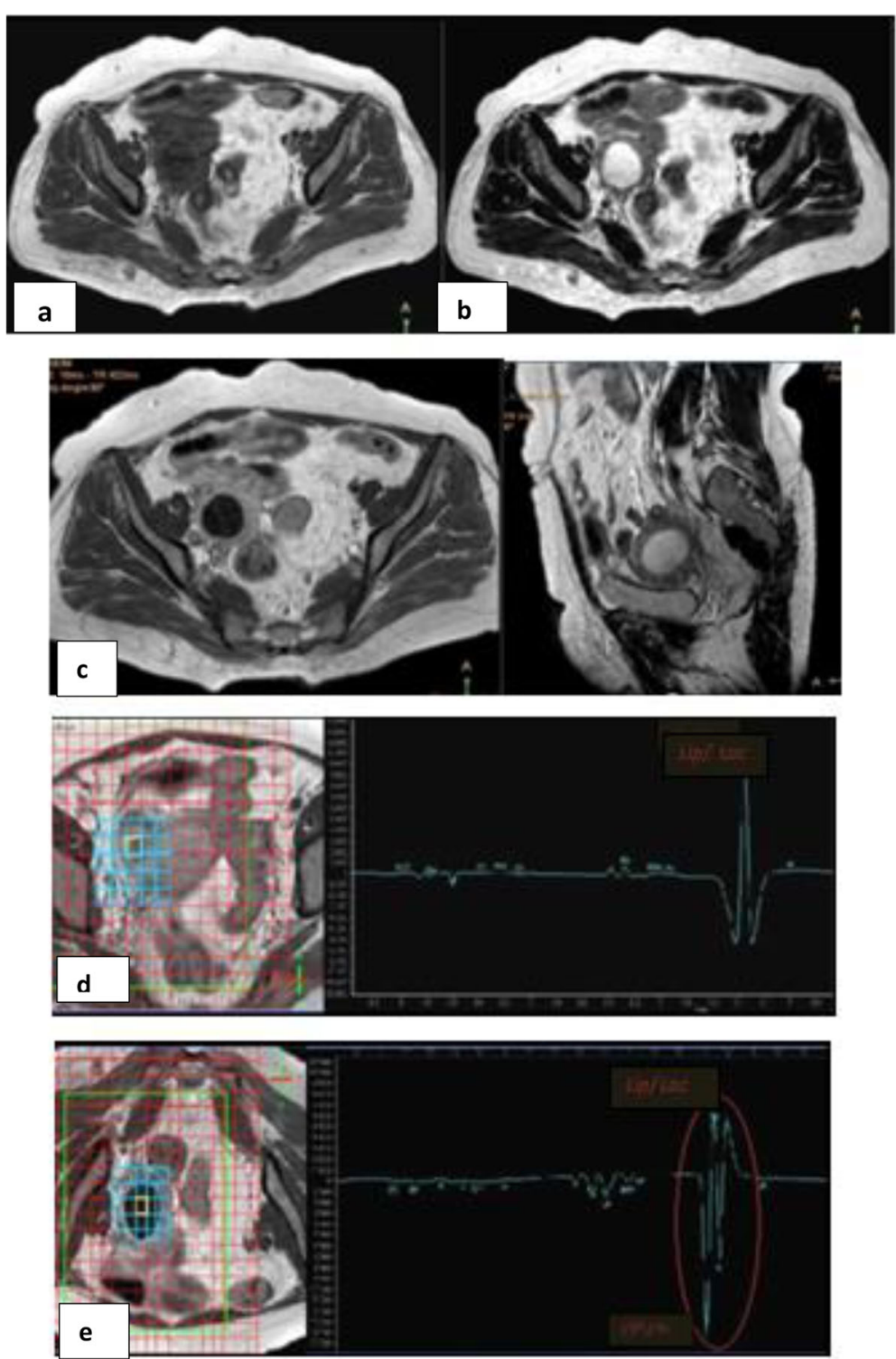

Fig. 1 Female patient, 60 years old, complaining of lower abdominal pain for 5 months. US showed right adnexal complex cystic mass with soft tissue component. a-d Conventional MRI images confirmed the presence of right adnexal complex cystic mass measuring $6 \times 5 \times 5 \mathrm{~cm}$ AP, C.C, and TS with central cystic component shows hypo-intense signal in T1WI and hyper intense signal in T2Wl, and its solid component with intermediate signal in both T1WI and T2WI and faint contrast enhancement in post-contrast image. e, f Proton MRS (TE = $288 \mathrm{~m} \mathrm{sec}$ ) a multivoxel into the solid component and into the cystic component of the mass respectively; a sharp lipid, lactate peak is observed around 1.3 ppm in both. Conventional MRI-based diagnosis: Malignant looking right adnexal complex cystic mass inseparable from adjacent bowel loops; MRS diagnosis: Confirm the malignant nature of the lesion with Cho/Cr ratio 2.27; Pathological diagnosis: Serous cyst adenocarcinoma

cases; 37 of them were benign (TN), misdiagnosed 3 cases were diagnosed as being benign (FN); ( 2 cases of borderline serous cystadenoma and a case of malignant immature teratoma) (Table 8). Two cases of borderline papillary serous cystadenoma showed lactate, lipid, and NAA peaks like cases of benign serous cystadenoma but both of them showed suspicious features in MRI. A case of malignant immature teratoma showed only lipid peaks with its peak values were much lower than its value in our cases of benign teratoma. MRS could not detect any other metabolites reflect the malignant nature of the mass it might be due to contamination of the voxel by the necrosis and heterogeneous nature of the tumor.

In our study, c MRI diagnostic performance in the assessment of adnexal lesions was 100\% sensitivity, 76\% specificity, and accuracy $86 \%$. A study carried out by Bekiesińska et al. (2007); the diagnostic accuracy of MRI 


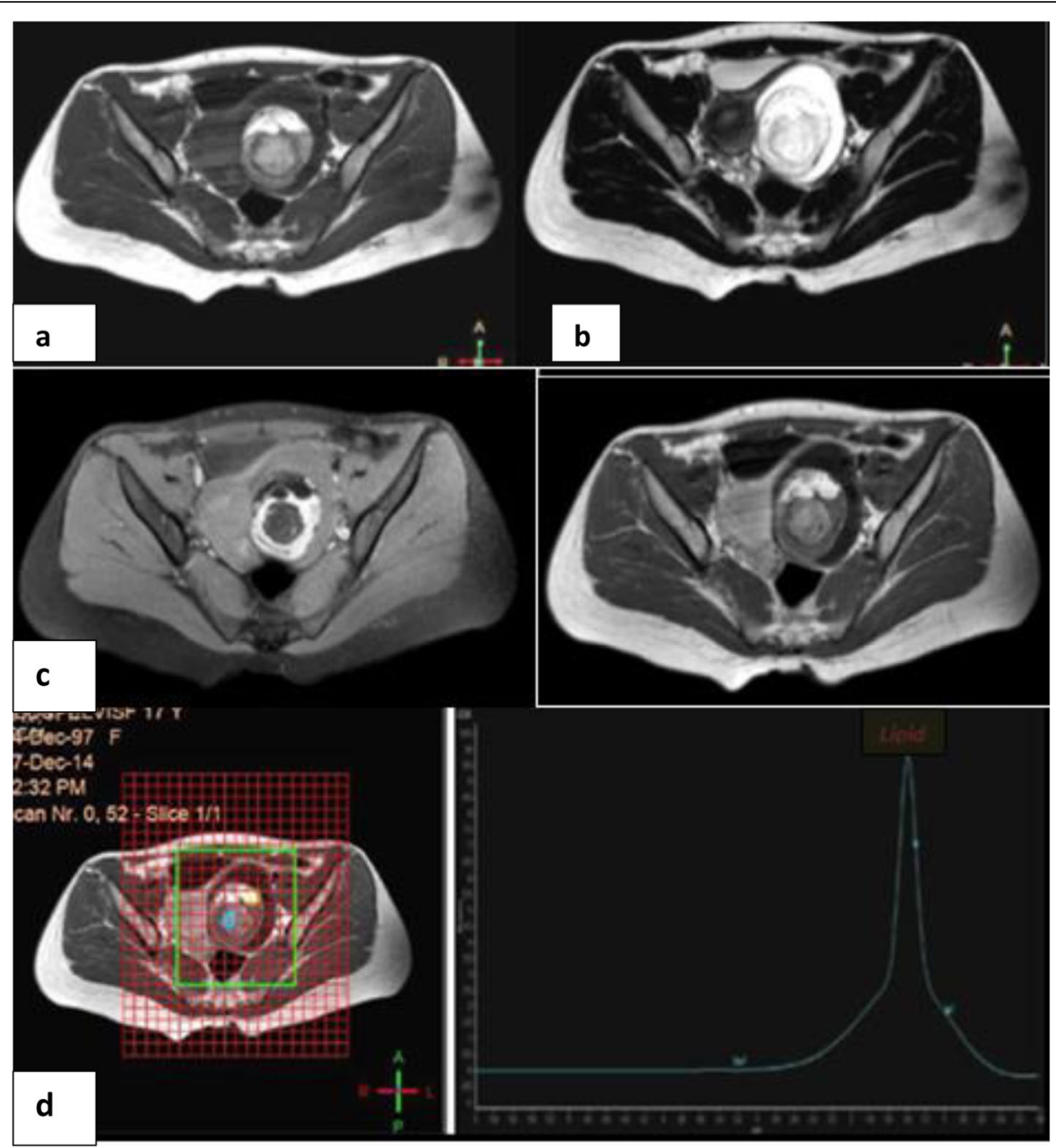

Fig. 2 Female patient, 17-year-old virgin, complaining of lower abdominal pain and progressive abdominal enlargement.US showed left adnexal complex cystic mass with solid component inside. a-d Conventional MRI images showed presence of large complex pelvi-abdominal adnexal mass. It measures $5 \times 8 \times 5.5 \mathrm{~cm}$ AP, C.C, and TS respectively. It elicited a hypo-intense signal in T1Wl and hyper-intense signal in T2WI of its cystic component, while the solid component inside shows areas of bright signal in T1WI and intermediate signal in T1WI suppressed on fat suppression. No solid enhancing masses seen on post contrast. e Proton MRS (TR $=1300 \mathrm{~m} \mathrm{sec}$, TE = $144 \mathrm{~m} \mathrm{sec)} \mathrm{observed} \mathrm{a} \mathrm{sharp} \mathrm{lipid} \mathrm{peak}$ around1.3 ppm in the solid component of the mass (high lipid content). Conventional MRI-based diagnosis: The patient was diagnosed as having benign complex left adnexal mass likely ovarian, mature cystic teratoma is highly considered; MRS diagnosis: Confirmed the benign nature of the mass with Cho/Cr ratio 0.29; Pathological diagnosis: Mature cystic teratoma

in characterizing ovarian lesions; it was $83.3 \%$ which is slightly lower compared with ours in which the diagnostic accuracy of MRI was $86 \%$ [20]. This difference could be due to the different number and nature of cases included in both studies. Another study performed by Rieber et al. (2001) on preoperative diagnosis of ovarian tumors with MRI. MRI had shown $83 \%$ sensitivity, $84 \%$ specificity, and $83 \%$ diagnostic accuracy, while in our results, MRI had shown higher $100 \%$ sensitivity and diagnostic accuracy (being 100\% and 86\% respectively) and lower specificity 76\% (Table 9) [21].

Regarding the diagnostic performance of MRS, a study conducted by MA and colleagues (2015) on MRS for differentiating benign from malignant solid adnexal tumors. The study included 69 patients with solid adnexal tumors (27 benign and 42 malignant) with a sensitivity of $94.1 \%$, specificity of $97.1 \%$, and an accuracy,91.2\% respectively [10]. In our study, MRS had shown lower sensitivity $89 \%$, however, higher specificity and accuracy of $100 \%$ and $95 \%$ respectively (Table 9 ).

MRS is optional cost-effective imaging. It provided good information about the different metabolites in the different ovarian lesions. MRS does not require the IV contrast administration, thus it can be used safely in pregnant patients and patients with renal dysfunction. However, MRS has few drawbacks; it depends on field 


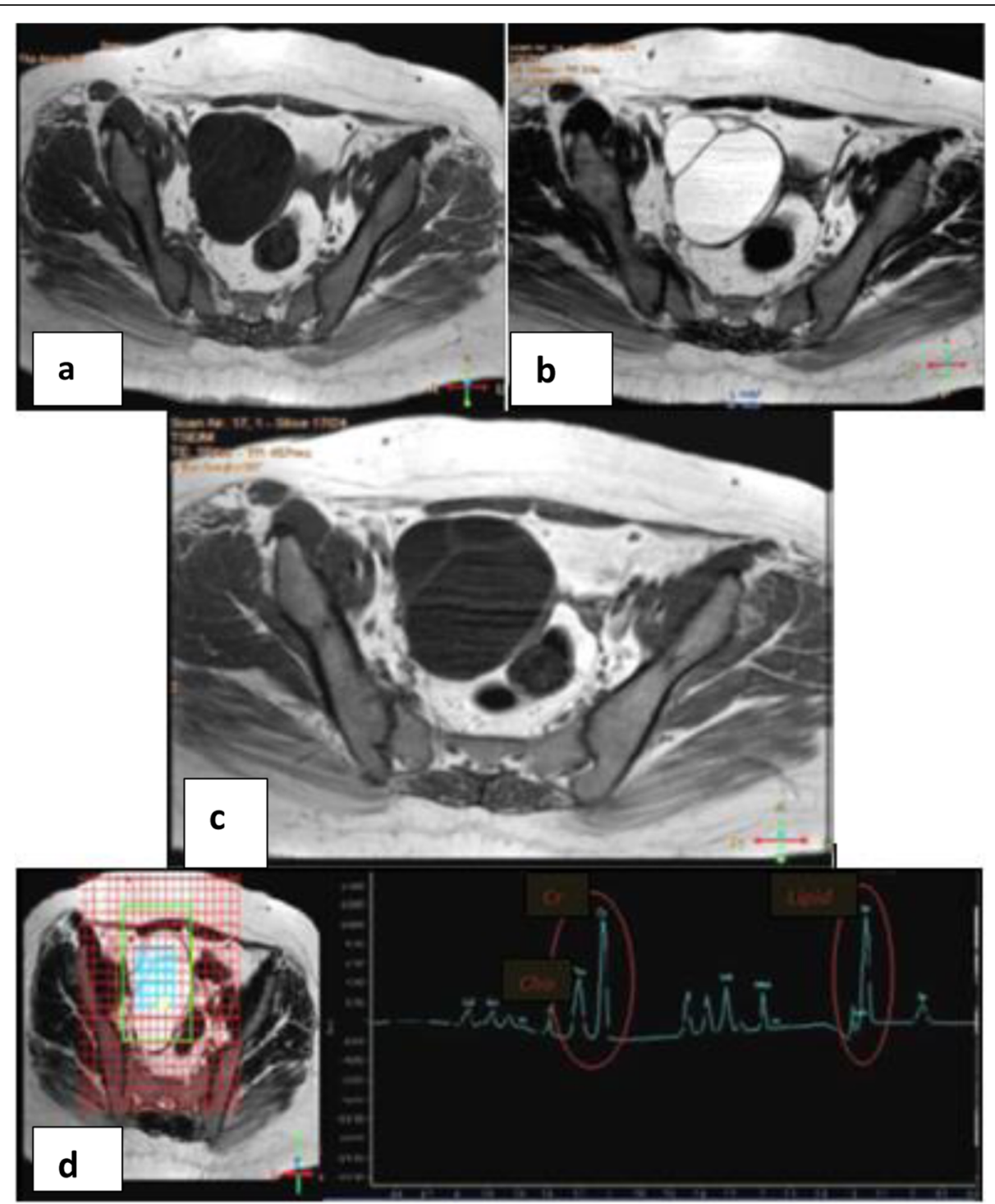

Fig. 3 Female patient, 58 years old, presented with lower abdominal pain.US showed right adnexal cystic mass, multilocular with septations. a-c Conventional MRI images showed a large right adnexal multilocular cystic mass with thick wall and septations; it measures $9.5 \times 10 \times$ $7.5 \mathrm{~cm}$ AP, C.C, and TS respectively. It shows hypo-intense signal in T1WI and hyper-intense signal in T2Wl, with enhanced wall and septae on post-contrast image. $\mathbf{d}$ Proton MRS (TE $=288 \mathrm{~m} \mathrm{sec}$ ) observed a sharp lipid and creatine peaks around $1.3 \mathrm{ppm}$ and 3 ppm respectively, another small choline peak is observed around $3.2 \mathrm{ppm}$. Conventional MRI-based diagnosis: borderline ovarian tumor; MRS diagnosis: confirmed the benign nature of the lesion with $\mathrm{Cho/Cr}$ ratio 0.45 ; Pathological diagnosis: benign serous cyst adenoma

homogeneity, so voxels should be selected carefully to avoid contamination from surrounding structures. Also, the respiratory movement in the pelvis contributes to the field inhomogeneity which may produce noisy spectra. Another major drawback is the longtime of examination (about $10 \mathrm{~min}$ ), which is not practical with old and claustrophobic patients [22].

This study has many limitations, first of all is the limited sample size, which may affect the diagnostic values presented by the MRI and MRS. We recommend another extended broad analysis with more biologically variable range of tumors especially malignant cases for proper evaluation of metabolic differences in malignant and benign lesions, proper estimation of the metabolite cut off value, and to improve the ways of the noninvasive preoperative diagnosis. Another limitation is that the size of the voxel needed to attain an adequate SNR ratio to discover the presence of malignancy. In very small lesions, the sensitivity to differentiate benign from malignant lesions decrease due to partial volume effects. To overcome this limitation, MRS should be performed using higher field strengths with high SNR and smaller voxel sizes. 

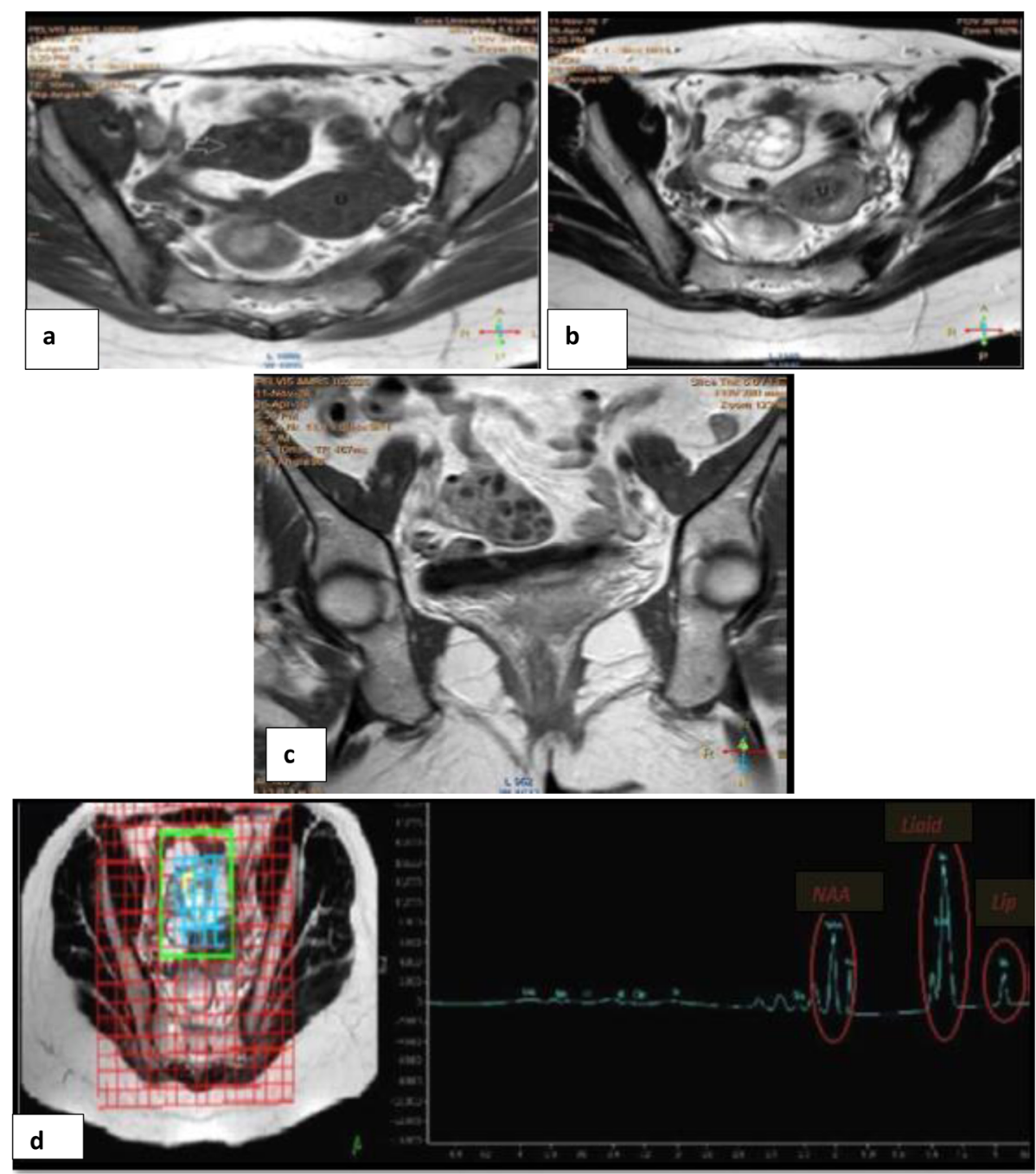

Fig. 4 Female patient, 40 years old, with history of right ovarian cystectomy, accidentally discovered right ovarian cystic mass by US.

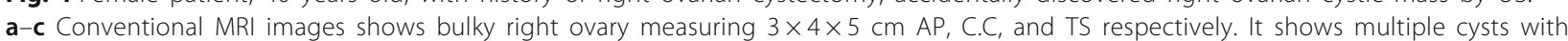
thickened wall as well as thickened septations. The cysts elicit hypo-intense TI signal and hyper-intense T2 signal, while the ovarian stroma shows intermediate to hypo-intense signal in T1WI and intermediate signal in T2Wl with heterogeneous contrast enhancement of the thick wall and septations in post-contrast image. $\mathbf{d}$ Proton MRS (TE $=288 \mathrm{~m} \mathrm{sec}$ ) observed a sharp lipid peak around $1.3 \mathrm{ppm}$ and another small lipid peak is noticed around 0.9 ppm. A sharp NAA peak can also be observed around 2 ppm, Conventional MRIbased diagnosis: right-sided borderline ovarian tumor is highly considered; MRS diagnosis: confirmed the benign nature of the lesion with Cho/Cr ratio 0.67; Pathological diagnosis: granulosa cell tumor

\section{Conclusion}

MRS added useful information for differentiating benign from malignant ovarian neoplasm; especially by using the $\mathrm{CHO} / \mathrm{Cr}$ ratio. MRS can confirm or exclude potential malignancy in complex adnexal masses, provided inclusion of the c MRI data. Also, the addition of MRS to the c MRI help in the characterization of indeterminate masses and has markedly improved its diagnostic value. Continuous MRS researches should be done to establish optimum diagnostic criteria and to improve their diagnostic value.

\section{Abbreviations}

BOTs: Borderline ovarian tumors; C MRl: Conventional MR imaging; CHO: Choline; CHO/Cr: Choline/creatine; MRS: Magnetic resonance spectroscopy; NAA: N-acetyl aspartate; NPV: Negative predictive value; PPV: Positive predictive value; ROI: Region of interest; US: Ultrasonography

\section{Acknowledgements}

Not applicable.

\section{Authors' contributions}

All authors have read and approved the manuscript. LEl conceived the study. LEl and RI participated in the study design. ZM carried out the data acquisition. LEl, RI, and MSh performed the data analysis and interpretation. $\mathrm{Rl}$ performed the statistical analysis. ZM, RI, and MSh prepared the 
manuscript. RI performed the manuscript editing. LEI and MSh reviewed the manuscript.

\section{Funding}

Self-funding.

\section{Availability of data and materials}

The datasets used and/or analyzed during the current study are available from the corresponding author on reasonable request.

\section{Ethics approval and consent to participate}

This study was approved by Radiology Department, Kasr Al-Aini Cairo University Hospital, research ethics committee. Number: not available. Written informed consent was signed by patients.

\section{Consent for publication}

All patients included in this research gave written informed consent to publish the data contained within this study.

\section{Competing interests}

The authors declare that they have no competing interests.

\section{Author details}

${ }^{1}$ Radiology Department, Kasr El-Ainy Hospital, Cairo University, Cairo, Egypt. ${ }^{2}$ Diagnostic Radiology, National Hepatology and Tropical Medicine Research Institute, Cairo, Egypt.

Received: 29 November 2019 Accepted: 2 December 2019

Published online: 17 December 2019

\section{References}

1. Shahid MK, Jamal R, Katherine LC, Monica PH, Linus C, Josef M et al (2011) Role of FDG PET/CT in staging of recurrent ovarian Cancer. Radiographics 31:569-583

2. Adusumilli S, Hussain HK, Caoili EM, Weadock WJ, Murray JP, Johnson TD et al (2006) MRI of sonographically indeterminate adnexal masses. AJR Am J Roentgenol 187(3):732-740

3. Mohaghegh P, Rockall AG (2012) Imaging strategy for early ovarian cancer: characterization of adnexal masses with conventional and advanced imaging techniques. Radiographics 32(6):1751-1773

4. El Sorogy L, Abd El Gaber N, Omran E, Elshamy M, Youssef H (2012) Role of diffusion MRI and proton magnetic resonance spectroscopy in characterization of ovarian neoplasms. EJRNM 43(1):99-106

5. Z Zhang P, Cui Y, Li W, Ren G, Chu C, Wu X (2012) Diagnostic accuracy of diffusion-weighted imaging with conventional MR imaging for differentiating complex solid and cystic ovarian tumors at 1.5T. World J Surg Oncol 10:237

6. Sarac K, CeliK O, Hascalik S, Ytre-Hauge S, Esmaeili M, Sjobakk TE et al (2004) In vivo proton magnetic resonance spectroscopy in the evaluation of the endometrium. Acta Obstet Gynecol Scand 83:751-757

7. Foti PV, Attina G, Spadola S, Caltabiano R, Farina R, Palmucci S et al (2016) MR imaging of ovarian masses: classification and differential diagnosis. Insights Imag 7(1):21-41

8. Zhao SH, Qiang JW, Zhang GF, Boyko OB, Wang SJ, Cai SQ et al (2014 Jul) MRI appearances of ovarian serous borderline tumor: pathological correlation. JMRI 40(1):151-156

9. Lyer VR. \& Lee SI. MRI/CT and PET/CT for ovarian cancer detection and adnexal lesion characterization, AJR Am J Roentgenol 2010; 194(2): 311-321

10. Ma FH, Oiang JW, Cai SO, Zhao SH, Zhang GF, Rao YM (2015) MR spectroscopy for differentiating benign from malignant solid adnexal tumors. AJR 204:W724-W730

11. Maheshwari SR, Fatterpekar GM, Castillo M, Mukherj SK (2000) Proton MR spectroscopy of the brain. Semin Ultrasound CT 6:434-451

12. Malek M, Pourashraf M, Mousavi AS, Rahmani M, Alipour A, Hashemi FS et al (2015) Differentiation of benign from malignant adnexal masses by functional 3 tesla MRI techniques: diffusion-weighted imaging and timeintensity curves of dynamic contrast enhanced MRI. Asian Pac J Cancer Prev 16:3407-3412

13. Stanwell P., Russell P., Carter J., Pather S.,Heintze S., C Mountford. Evaluation of ovarian tumours by proton magnetic resonance spectroscopy at three tesla. Investig Radiol 2008; 43: 745-751
14. Xu S, Yang J, Shen J (2008) Measuring N-acetyl aspartate synthesis in vivo using proton magnetic resonance spectroscopy. J Neurosci Methods 172:812

15. Miller B (1992) A review of chemical issue in H1NMRS: NAA, creatine and choline. NMR Biomed 4:47-52

16. Takeuchi M, Matsuzaki K, Harada M (2011) Preliminary observations and clinical value of $\mathrm{N}$-acetyl resonances in ovarian tumours using in vivo proton MR spectroscopy at 3 T. Eur Radiol 21(12):2640-2646

17. Okada T, Harada M, Matsuzaki K, Nishitani H, Aono T (2001) Evaluation of female intrapelvic tumors by clinical proton MR spectroscopy. JMRI 13(6): 912-917

18. Fiaschetti V., Fabiano S., Chiaravalloti A., Morosetti D., BELLAFIORE I., Simonetti G., et al. In vivo magnetic resonance spectroscopy of ovarian lesions at 3.0 Tesla. ECR 2012; https://doi.org/10.1594/C-0835

19. Hascalik S, Celik O, Sarac K et al (2005) Metabolic changes in pelvic lesions: findings at proton MR spectroscopic imaging. Gynecol Obstet Investig 60: 121-127

20. Bekiesińska M, Jurkiewicz E, Iwanowska B, Uliasz M, , Bragoszewska H, Ceran A, et al. Magnetic resonance imaging as a diagnostic tool for ovarian masses in girls and young women. Med Sci Monit 2007; 13: 116-120

21. Rieber A, Nüssle K, Stöhr I, Grab D, Frenchel S, Kreienberg R et al (2001) Preoperative diagnosis of ovarian tumors with MR imaging: comparison with transvaginal sonography, positron emission tomography, and histologic findings. AJR 177:123-129

22. Cho SW, Cho SG, Lee JH, Kim HJ, Lim MK, Kim JW et al (2002) In-vivo proton magnetic resonance spectroscopy in adnexal lesions. KJR 3(2):105-112

\section{Publisher's Note}

Springer Nature remains neutral with regard to jurisdictional claims in published maps and institutional affiliations.

\section{Submit your manuscript to a SpringerOpen ${ }^{\circ}$ journal and benefit from:}

- Convenient online submission

- Rigorous peer review

- Open access: articles freely available online

- High visibility within the field

- Retaining the copyright to your article

Submit your next manuscript at $>$ springeropen.com 